\title{
O PAPEL DAS ORGANIZAÇÕES FRENTE Á PRECARIZAÇÃO DO TRABALHO NO SÉCULO XXI
}

\section{THE ROLE OF ORGANIZATIONS FRONT WILL WORK PRECARIOUSNESS ST CENTURY}

\author{
Ana Paula Lima Azevedo ${ }^{1}$ \\ Lígia Paula Marinho Pinto Honório ${ }^{2}$ \\ Lúcia de Fátima Nepomuceno dos Santos $^{3}$ \\ Raphael de Souza Pires ${ }^{4}$
}

\section{RESUMO}

O artigo pretende apresentar uma reflexão sobre a precarização do trabalho no século XXI, a partir de uma perspectiva histórica e estudo bibliográfico. Analisamos como a sociedade vem adaptandose com as transformações advindas do Século XXI, determinadas pelas condições econômicas, sociais e tecnológicas inseridas no mundo do trabalho, bem como suas influências e possíveis contribuições para a melhoria na relação homem e trabalho, e quais as principais consequências favorecem a precarização do trabalho e sofrimento na ambiência do mesmo. O estudo apoia-se na fundamentação teórica dos autores MARX (2006) MARCUSE (1964) e DEJOURS (1992). Neste, afigura-se como central questão, apontar caminhos e possibilidades para resignificação da relação homem trabalho com autorrealização.

PALAVRAS - CHAVE: Trabalho - Precarização - Mediação Organizacional.

\section{ABSTRACT}

The article aims to present a reflection on the precariousness of work in the twenty-first century, from a historical perspective and bibliographical study. We look at how society is adapting to the changes arising from the twenty-first century, determined by economic, social and technological conditions inserted in the working world and its influences and possible contributions to the improvement in man and working relationship, and what are the main consequences favor the precariousness of work and suffering in the ambience of it. The study is based on theoretical basis of the authors MARX (2006) Marcuse (1964) and DEJOURS (1992). In this, it appears as a central issue, point out ways and possibilities for reframing the relationship between man and work with 
self-fulfillment.

KEY - WORDS: Work - Precariousness - Organizational Mediation.

\section{INTRODUÇÃO}

As mudanças de paradigmas na construção histórica do trabalho e do homem para Marx, (2006) é uma relação de sociabilidade, a construção da sua identidade e da sua inserção na sociedade.

Duas características essenciais diferenciam segundo Marx, o capitalismo dos outros sistemas econômicos: a separação do produtor dos meios de produção, dando origem a uma classe de proprietários e uma classe de trabalhadores e a infiltração do mercado, ou do nexo monetário, em todas as relações humanas, tanto na esfera da produção quanto na esfera da distribuição.

Marx partiu dessas questões que o fez denunciar com mais veemência em sua crítica ao sistema capitalista, traduzindo para o autor a completa degradação e desumanização da classe operária, a deformação do desenvolvimento da personalidade do homem e a transformação das atividades necessárias para a sua sobrevivência em mercadorias submetidas às leis hostis do mercado.

O capitalismo industrial é uma nova fase desse sistema econômico no qual Marx se refere em suas análises, que surge em meio a um processo de revoluções políticas e tecnológicas, na segunda metade do século XVIII. Com essa nova fase é superado o capitalismo comercial, também chamado de mercantilismo, que surgiu no fim do século XIV e vigorou até então. Muitos fatores econômicos, sociais e políticos contribuíram para o desenvolvimento dessa nova forma de capitalismo. (nota de roda pé 01 informações dos autores)

A engenhosidade do sistema capitalista é assumir diferentes formas de adequar-se com facilidade às constantes transformações na economia de mercado e de não perder de vista o seu papel ideológico de expropriação da força de trabalho e mais valia.

$\mathrm{Na}$ economia, o grande impacto foi impulsionado pelas transformações nas técnicas e no modo de produção. As máquinas passaram a ser utilizadas em larga escala, tornando ultrapassados os métodos de produção anteriores, de caráter artesanal. Esse processo ficou conhecido como Revolução Industrial e teve seu início na Inglaterra.

Tanto do ponto de vista da economia, quanto da política, outra transformação importante foi a independência dos Estados Unidos, a chamada Revolução Americana, de 1776. Ela constituiu o primeiro grande abalo numa das bases do mercantilismo, o sistema colonial, em que as colônias americanas, africanas ou asiáticas se mantinham submissas aos interesses das metrópoles europeias. 
Segundo Marx, (2006) esse sistema econômico não vê nenhum impedimento político, moral ou ético para expropriar o trabalhador de todos os seus atributos humanos.

Marx afirma que no processo de produção capitalista, o homem se aliena, tornando-se mera peça de engrenagem produtiva. Ele não é mais dono dos seus instrumentos de trabalho, o ritmo de produção não é determinado por ele e tampouco domina o processo produtivo por completo, em decorrência da divisão do trabalho.

A principal consequência desse processo é que o trabalhador não se reconhece no produto que fez, e assim, perde a sua identidade enquanto sujeito.

Marcuse, (1964) estabelece um relação de alinhamento com o pensamento de Marx. Utilizase do materialismo histórico ${ }^{5}$ de Marx para analisar o homem e suas relações em sociedade. No contexto do capital, emerge a divisão social do trabalho reforçando a separação entre os que dirigem e os que executam o processo de trabalho.

Nesta situação o trabalhador é constrangido a atender suas necessidades mais imediatas, tais como: comer, beber, vestir, etc., se não o fizer, porá em risco sua própria existência. Ao fazer de sua capacidade de trabalho um meio para atingir determinados fins, a sua atividade deixa de ser uma atividade livre (auto-atividade) e torna-se trabalho imposto pelas necessidades sociais e individuais de cada sujeito.

Marcuse, (1964) ressalta que o indivíduo não percebe que está sendo manipulado pelo interesse do capital a ampliar sua necessidade de consumo em consequência das suas necessidades cada vez mais latentes de consumir bens materiais, atrelando a falsa ideia de qualidade de vida e conforto. Deixando de levar em consideração que para manter o status precisa sacrificar o tempo com sua família e aumentar a sua permanência no ambiente de trabalho. Nessa perspectiva a Razão "faculdade humana" que se manifesta no uso completo feito pelo homem de suas possibilidades, passa assumir uma postura de subserviência e deixa de compreender as "possibilidades" percebendo somente as "necessidades", voltando-se a atender os interesses do capital, ou seja, a Razão fica em segundo plano. O instrumento potencializador da subserviência do homem e mecanismo de controle advém das inovações tecnológicas.

A tecnologia, para Marcuse, bem como o modo de produção, como a totalidade dos instrumentos, dispositivos, invenções tecnológicas, colocam-se como mecanismos de controle passando a construir uma forma de organizar e modificar as relações sociais. Reproduz a manifestação do pensamento e dos padrões de comportamento dominantes. Enfim, trata-se de um verdadeiro instrumento de controle e dominação. E isso ocorre em razão da organização do aparato industrial, voltado totalmente para a satisfação das necessidades crescentes dos indivíduos. Em virtude do modo pelo qual organizou a sua base tecnológica, a sociedade industrial contemporânea tende a tornar-se totalitária. (MARCUSE, 1964, p.24) 
A sociedade industrial é totalitária no sentido de agir como um sistema de controle social e político, por meio de manipulação para atingir seus interesses. Bem como, para definir o sistema específico de produção e distribuição em massa, que existe em razão da manipulação do poder inerente à tecnologia, na eficiência da produção e no desempenho do trabalho humano.

O comportamento humano passa a ser regido pela racionalização do pensamento tecnológico que coloca a máquina como o centro e o homem um complemento do processo. A máquina é mais relevante do que o trabalhador que a opera, deixando de levar em consideração que por mais auto suficiente que seja o maquinário, tem a necessidade da ação humana, pois é o homem que detém a capacidade e possibilidade de criação, desenvolve a tecnologia afim de favorecer e aumentar a produtividade e a competitividade atreladas aos interesses econômicos. Partindo desse pressuposto qual o papel da tecnologia no mundo do trabalho?

Segundo HERÉDIA (2004), a inserção de novas tecnologias ocasionou uma série de efeitos sociais que afetaram os trabalhadores e sua organização. Efeitos esses denominados de "impactos sociais", repercutiram significativamente nos processos de trabalho, na qualificação da força de trabalho, nas próprias condições de trabalho, e principalmente na saúde do trabalhador e consequentemente nas políticas de ocupação, afetando diretamente a questão do emprego. É a partir dessa perspectiva que se constitui o nosso estudo.

\section{RELAÇÃO HOMEM, TRABALHO E TECNOLOGIA}

A mudança de paradigma tecnológico implica transformações substantivas na organização do trabalho. Passa a ser um imperativo dos sistemas político, econômico e social para os indivíduos e para a empregabilidade, levando em consideração que a educação geral é tomada como requisito indispensável ao emprego formal e regulamentado, ao mesmo tempo em que deveria desempenhar papel preponderante na condução de políticas sociais, educacionais e econômicas de cunho compensatório, que visem à contenção da pobreza.

Considerando o contexto citado, aqui sinteticamente caracterizado, direciona uma nova orientação para as transformações no mundo do trabalho dos países mais pobres e populosos com o objetivo de aumentar os investimentos no setor tecnológico.

Quando o modo de produção e organização econômica e social se firma capitalista, tende-se a fazer nas instituições a internalização dos valores e ideologia dominante da produtividade reproduzindo mecanismos de preservação do sistema vigente. Assim com as transformações constantes e ininterruptas impulsionadas com a globalização econômica e a hegemônica política neoliberal se muda de valores e de funções afetando o trabalhador que tem que se adequar às 
transformações das novas dinâmicas de produção.

O acesso ao trabalho é visto na atual sociedade como principal meio de distribuição de renda e garantia de mobilidade social. Será combinada à noção de que o acesso, hoje à cultura escrita, letrada e informatizada é inevitável e constitui-se no único meio de ingressar ou permanecer no mercado de trabalho ou, ainda, sobreviver na chamada sociedade do terceiro milênio (Delors, 1998).

Essas reformas acabarão por determinar uma reestruturação do trabalho, resultante da combinação de diferentes fatores que se farão presentes também na gestão e na organização do trabalho, tendo como corolário maior a responsabilização e envolvimento dos trabalhadores no uso de novas tecnologias. Nesse viés envolve a assimilação de uma cultura empresarial onde haja a integração entre as propostas de modernização tecnológica e racionalização.

\section{PRECARIZAÇÃO, TRABALHO E EDUCAÇÃO}

O uso de novas tecnologias nem sempre é apenas um processo técnico na medida em que pressupõe uma nova orientação no controle do capital, no processo produtivo e na qualificação da força de trabalho. Dos diversos efeitos que derivaram dessa orientação, a terceirização, a precarização e a flexibilidade aparecem com constância como características do paradigma flexível, em substituição ao taylorista-fordista ${ }^{6}$ (HERÉDIA, 2004).

As situações provocadas pela inovação constante nos processos de trabalho, têm contribuído para o desemprego dos trabalhadores com mais idade que não conseguem acompanhar as mudanças postas pelo avanço tecnológico que saem do trabalho formalizado e por questões de sobrevivência adentram no mercado informal que absorve essa mão de obra mais barata com condições insalubres de um trabalho precarizado.

Isso ocorre na maioria das vezes nas grandes indústrias no setor operacional "chão de fábrica". Segundo Geller, (apud,1998) a redistribuição de trabalhadores entre setores é um fenômeno contínuo, ligado ao processo tecnológico e ao crescimento produtivo. Entretanto a relocação de trabalhadores entre setores é problemática quando a indústria não possui programas de requalificação de sua força de trabalho. Quando o trabalhador passa a não corresponder as constantes adaptações advindas das inovações tecnológicas ocorre o desligamento.

Verifica-se a seguinte questão: ter o acesso à educação com as qualificações exigidas a partir da nova organização do trabalho, garante a inserção e permanência no mercado formal de trabalho no Brasil? Geller (apud,1998) percebe que os critérios de qualificação profissional perpassam as exigências da escolaridade formal, criando uma distância da escola com o mundo do trabalho. 
Habilidades como ler, escrever, calcular não bastam para qualificar um trabalhador tecnicamente. A mudança tecnológica faz parte de um processo contínuo que exige novas competências. Estar atento às exigências do mercado e responder às suas demandas, não é uma tarefa simples, principalmente porque as mudanças tecnológicas têm sido acompanhadas por mudanças organizacionais, decorrentes das mudanças de paradigmas.

Para compreender porque esses fenômenos estão ocorrendo no mundo trabalho na perspectiva do Brasil, FOGAÇA, A; SALM, (2006), analisam esses acontecimentos em três aspectos: o primeiro parte de observação mais geral, mesmo com os avanços democráticos ao acesso à educação, em nossa sociedade ainda perpassa a ideia de que todos somos iguais, mas uns são mais iguais do que os outros, ou seja, estamos inseridos no sistema ditame que diz quem merece ter todas as oportunidade e outros que não merecem. Daí decorre a precarização na formação da classe trabalhadora que não consegue, pelas condições sociais desiguais postas pelo sistema, investir na sua formação profissional por conta da precarização em que vivem.

O segundo: refere-se ao empresariado e às hierarquias empresariais, nas quais, no Brasil, concebe-se o preconceito de que as inovações não podem surgir no chão-de-fábrica, isto é, de que o trabalhador que atua no operacional não pode exercer sua capacidade criadora e muito menos ter autonomia nas funções desempenhadas no trabalho. Daí se explica o comportamento da maioria das empresas que modernizam seus processos investindo muito na aquisição de maquinário importado e investe acanhadamente na qualificação e participação dos trabalhadores na democratização das relações de trabalho.

A consequência é que deixam de transformar maiores ganhos de produtividade em melhores salários. Embora grande parte dos empresários considerem que a escolarização do trabalhador é um fator imprescindível para desempenhar suas atribuições. O pouco que ainda se investe volta-se mais fortemente para os segmentos de gestão, ou seja, para a categoria dos gestores que já possui formação, para o operacional "chão de fábrica" como são denominados, o investimento é considerado quase imperceptível.

O terceiro aspecto: apresenta-se pela manipulação na esfera política, utilizando-se da educação como moeda eleitoreira, apresentando políticas educacionais voltadas para qualificação do trabalhador na modalidade do ensino técnico. No entanto, o acesso dos trabalhadores que estão inseridos no mercado de trabalho com a permanência comprometida por dificuldade em acompanhar a inovações tecnológicas, apenas uma pequena minoria consegue dar continuidade no seu processo de formação. A adesão por parte desse perfil é mínima, devido absorverem uma carga de trabalho intensa e seu tempo fica escasso, bem como a falta de recurso financeiro para investir na sua formação.

Daí explica-se a ineficácia das políticas públicas educacionais e sociais de acessibilidade 
diante do fraquíssimo desempenho do sistema educacional e das evidências de que grande parte dos problemas sociais que temos está associada à baixa escolaridade. Segundo ORSO (2014), não podemos ver as reformas educacionais como algo isolado da sociedade, pois elas são influenciadas pelas implicações da globalização econômica e da hegemônica política neoliberal.

FOGAÇA; SALM, (2006) afirma que apontar a educação como uma ferramenta importante para esse desenvolvimento com justiça social, soa bem no discurso, mas não transforma a prática, porque, na verdade, a pobreza é funcional aos que colhem os melhores frutos desse nosso modelo de sociedade. Neste contexto, o panorama geral da educação brasileira nos autoriza a crer que ainda conviveremos por muito tempo com estratégias econômicas que não correspondem à efetiva superação do subdesenvolvimento.

Os autores em consonância pretendem nos afastar das utopias do pedagogismo reformista, segunda as quais a expansão e democratização do acesso à educação para todos seriam uma forma de garantir a mobilidade social das classes baixas, melhoria das suas condições de vida, seria um antídoto a quase todos os problemas individuais e sociais.

Esta análise socioeconômica das transformações do trabalho faz perceber a massificação do ensino como os degraus da libertação dos trabalhadores das malhas da exploração e dominação que se devia a seu baixo nível de formação. Essa educação assume um papel messiânico, porque combate a grande ameaça contra a estabilidade e a ordem social: a ignorância do povo, em especial a das classes baixas.

\section{CAUSAS E CONSEQUÊNCIAS DO SOFRIMENTO NO TRABALHO}

Segundo Dejours (1992), as diferentes formas de gestão da organização, as estratégias, e os métodos de defesa do trabalhador frente às causas do prazer e do sofrimento são decorrentes da organização do trabalho. $\mathrm{O}$ autor nos ajuda a compreender a significação do trabalho, sabendo que essa relação não pertence à psicopatologia do trabalho e sim aos processos psicossociais que interferem nas pessoas e nas organizações influenciando sobre a saúde mental do trabalhador.Sabendo que essa relação entre o psíquico do trabalhador e a organização poderá ser ponto de equilíbrio entre a mente e o corpo, apoiado numa boa análise da psicodinâmica da relação homem-trabalho. Respeitando as necessidades do trabalhador e as exigências do trabalho.

O indivíduo dentro de uma organização passa por determinadas cargas de exigências mentais ou psíquicas no trabalho que quando acumuladas podem desencadear tensões psíquicas e psicossomáticas, que necessitam ser canalizadas de forma correta para que essas experiências não possam lhe causar prejuízos maiores. Esta via de descarga o indivíduo deveria encontrar dentro da 
empresa a fim de assegurar seu equilíbrio. MILANESI, COLLET, VIERA; OLIVEIRA, (2003)

O trabalhador passa a ser cobrado a responder as exigências que estão além de sua formação e assume essa obrigatoriedade vinculando garantir sua permanência no trabalho. Muitas vezes, esses profissionais são obrigados a desempenhar funções que diferem das atribuições do cargo que ocupa, absorvendo muitas funções e sendo alocados em diferentes setores. Neste momento, o trabalhador é submetido a situação de vulnerabilidade, uma vez que, é obrigado pela excessiva demanda de trabalho e ao cumprimento das metas no tempo previsto, quando não consegue, passa ser cometido por sentimentos que desencadeia angústia e sofrimento interno.

Tais exigências contribuem para um sentimento de desprofissionalização, de perda de identidade profissional. Essa situação é ainda mais reforçada pelas estratégias de gestão já mencionadas, que apelam ao comunitarismo e voluntariado com argumentação de ascensão profissional. Nesse contexto, é que se identifica um processo de desqualificação e desvalorização sofrido pelos trabalhadores. As reformas em curso tendem a retirar deles a autonomia, entendida como condição de participar da concepção e organização de seu trabalho.

O trabalho torna-se uma mercadoria cujo seu custo precisa ser diminuído para aumentar os ganhos dos proprietários e impulsionar os meios de produção, isso leva a intensificação do trabalho, acompanhado de baixos salários, que pauperniza, uma vez que o pouco que recebem tem como se reproduzirem enquanto trabalhador.

Consequentemente coloca o trabalhador em uma situação de precarização de sua vida social e econômica, comprometendo suas relações afetivas com a família, devido a falta de tempo e a sobrecarga de trabalho, colocando-o na situação de proletário, uma vez que como todo trabalhador é forçado a vender sua força de trabalho para sobreviver. Essas faltas corroboram para dar evasão às causas e consequências, às doenças de cunho psíquico devido a constante exposição de situações que proporcionam insatisfação, angústia e desmotivação no ambiente de trabalho dar-se-ão a partir do sofrimento.

O sofrimento começa quando a relação do homem-trabalho é bloqueada. Segundo Dejours (1992), o sentimento de inutilidade, a significação, que remete ao reconhecimento da finalidade do trabalho em relação ao conjunto de atividades exercidas na rotina do ambiente de trabalho é um potencializador para gerar angústia, insatisfação e sofrimento em decorrência da vivência diária desses sentimentos, fruto de rotinas excessivas de trabalho. Trata-se de uma imagem que começa a repercutir no trabalho, nas relações familiares e na sociedade. (DEJOURS, 1992, p 49.)

O sofrimento do indivíduo começa quando ele não encontra na organização uma forma de canalizar, deixando suas expectativas de desejo, motivação e reconhecimento fora da realidade da organização do trabalho, dando lugar a conflitos na relação homem-trabalho.

Para MILANESI, COLLET, VIERA e OLIVEIRA, (2003) na tentativa de fugir ou evitar o 
sofrimento, os trabalhadores usam defesas próprias de sua personalidade individual como: não se comunicar, deixam de ser criativos, passam a se preocupar somente consigo, desconfiam dos colegas de trabalho, rompendo assim o relacionamento para evitar conflitos. Essas estratégias mudam de pessoa a pessoa, por serem indivíduos singulares e terem objetivos específicos, eles reagem de forma diferente numa situação, podendo ser individuais ou coletivas para melhor se adaptarem ao ambiente de trabalho.

\begin{abstract}
A organização do trabalho determina o conteúdo da tarefa através da divisão do trabalho. A livre organização do trabalho é apenas uma estruturação do modo operatório, que leva em consideração, as atitudes individuais, as necessidades da personalidade, onde cada gesto harmoniza-se espontaneamente com as defesas comportamentais e caracteriais. A organização do tempo em fases de trabalho e fases de descanso respeita as necessidades da economia psicossomáticas, protege o corpo contra uma sobrecarga comportamental que poderia ser prejudicial, e possibilita ao sujeito meios de canalizar suas pulsões durante o trabalho. (DEJOURS, 1992 p. 127 e 128)
\end{abstract}

Quando as organizações adotam práticas de responsabilidade social, visando a integridade dos trabalhadores, valorizando o aspecto humano, social e sustentável, reconhecendo a importância e a universalidade dos direitos humanos, assegurando os direitos trabalhistas, cuidando para que as atividades nas organizações não os agridam direta ou indiretamente, zelando pelo ambiente econômico, social e natural que necessitam, as organizações passam a aderir ao novo modelo de gestão que apoia-se na diretriz Internacional ISO 26000, bem como as normas nacionais da ABNT de responsabilidade social que proporciona às empresas certificação de qualidade e um ambiente salubre de trabalho.

Um dos principais expoentes no estudo da questão, Walton (1973), articula a conceituação que segue: "a ideia de QVT (qualidade de vida no trabalho) é calcada em humanização do trabalho e responsabilidade social da empresa, envolvendo o entendimento de necessidades e aspirações do indivíduo, através da reestruturação do desenho de cargos e novas formas de organizar o trabalho, aliado a uma formação de equipes de trabalho com maior poder de autonomia e melhoria do meio organizacional". (TOLFO ; PICCININI, V. C. 2001)

Segundo (OLIVEIRA, N. T, 2003) o trabalho também pode assumir a posição de mediador atuando na passagem do sofrimento para o prazer, quando ocorre o equilíbrio entre as singularidades de cada trabalhador frente aos seus desejos, necessidades, resultados e interesses da organização gerando uma relação mais saudável para ambos. Quando as organizações adotam prática de responsabilidade social, visando a integridade reconhecendo a importância e a universalidade dos direitos humanos, cuidando para que as atividades da organização não os agridam direta ou indiretamente, zelando pelo ambiente econômico, social e natural de que necessitam.

Para Traesel e Megier, na psicodinâmica do trabalho o foco é o "trabalho e suas influências" na vida do sujeito, sejam psicológicas, físicas, culturais, políticas e econômicas que se manifestam 
no sofrimento e no prazer. Para que o trabalho tenha sentido para o trabalhador ele tem que ser reconhecido, valorizado e motivado para execução de suas tarefas.

O trabalho nos dias atuais, como ao longo tempo é fonte de grande importância para o ser humano. Sendo o trabalho um espaço de construção dos sentidos e de identidade. (OLIVEIRA, N. T, 2003).

No mundo competitivo em que vivemos, as organizações devem ter um modelo de gestão, onde o trabalhador não seja apenas cobrado por seus resultados, mas que possam exercer seu trabalho com liberdade, criatividade, satisfação, que possuam ambiente saudável e que sejam reconhecidos, valorizados e que o seu trabalho seja fonte de realização para ele e sua família. (TRAESEL; MEGIER, M.C 2012)

Reconhecer o trabalho do indivíduo permite compreender o destino do sofrimento no trabalho, seus esforços, suas dúvidas e decepções se transformarem em prazer e sua realização profissional e pessoal. (OLIVEIRA, N. T, 2003).

\section{CONSIDERAÇÕES FINAIS}

O presente artigo possibilitou o debate e reflexão sobre as possíveis causas da precarização do trabalho no século XXI, buscou elucidar os principais fenômenos que contribuem direta e indiretamente para a precarização do trabalho. Acreditamos que as categorias estudadas poderão contribuir para o debate acerca da relação homem-trabalho no contexto moderno.

A partir da pesquisa, concluímos que o mundo está em constante transformação, nos setores: econômico, político, social e tecnológico, implicando significativamente no mundo do trabalho. Isso ocasionou o surgimento de processos de trabalho cada vez mais eficazes e eficientes, modernidade e tecnologias que agregaram para as empresas e consumidores, aproveitamento de tempo, recursos e produtos de alto desempenho. Mediante o estudo realizado entende-se que a inserção de novas tecnologias ocasionou uma série de efeitos sociais que afetaram os trabalhadores estando relacionados com a qualificação da força de trabalho, as condições de trabalho, e principalmente na saúde do trabalhador comprometendo os fatores de autorrealização no ambiente de trabalho.

Partimos de uma perspectiva crítica para compreender que a mudança de paradigma ocasiona transformações substantivas na organização do trabalho, a precarização e o sofrimento do trabalhador, para destacar assim o papel e a importância das organizações e da gestão. Como mediadora neste contexto pode adotar uma postura de romper com o trabalho precarizado, aderindo práticas que valorizam a qualidade de vida no ambiente de trabalho como: equidade salarial, 
condições físicas seguras e salutares que respeita os limites do trabalhador, oportunidade de desenvolver suas capacidades, autonomia e visão integral do processo do trabalho, possibilidades contínuas de crescimento, desenvolvimento de carreira e segurança no emprego e integração social.

Atualmente no Brasil, e no mundo, observa-se um movimento por parte de algumas empresas que perceberam a relevância de investir no trabalhador, independente da posição hierárquica que ocupa dentro da organização. Implantando programas de qualificação para seus trabalhadores acompanharem as inovações tecnológicas, bem como programas de qualidade de vida que beneficiam o trabalhador e sua família. Dentro desse novo modelo adotado advindo do surgimento de novas tecnologias, da competitividade do mercado que buscam o diferencial para agregar valores aos seus negócios, adotando práticas que valorizam o grande potencial de seus trabalhadores tornando-os um diferencial competitivo no mercado.

Esse modelo vem se fortalecendo nas grandes empresas como: Google, Volvo Brasil, Elektro, Cervantes, Cielo, Grupo Boticário, Weber, Saint-Gobain, Weber Saint-Gobain, MSD Saúde Animal, Sama, Tribunal de Contas da União, International Paper, Dow Brasil, Algar Empreendimento e Participações, Laboratório Sabin, Gerdau, SAP Labs Latin America, Telefônica Vivo, Transpes e Gazin. Essas empresas foram eleitas pela revista Exame como as melhores empresas para se trabalhar no ano de 2014, propiciando um ambiente de trabalho que conseguem transcender o trabalho precarizado.

Este estudo teve como objetivo principal identificar os causas e consequências da precarização do trabalho no século XXI e apontar caminhos e possibilidades para resignificação da relação homem trabalho com autorrealização. Concluímos que a gestão da qualidade de vida no trabalho é uma ferramenta importante que possibilita as organizações, viabilizar programas que conseguem beneficiar tanto os trabalhadores como as organizações. Levando em consideração aspectos em relação ao bem estar dos funcionários, favorecendo um ambiente de satisfação e retenção de talentos, valorização da autonomia e criatividade dos trabalhadores na organização do trabalho. A pesquisa demonstrou que as organizações que adotam esse modelo de gestão de qualidade de vida no trabalho, conseguem obter bons resultados destacando-se no mercado e adquirindo visibilidade, credibilidade e crescimento.

\section{REFERÊNCIAS BIBLIOGRÁFICAS}

DEJOURS, C. A Loucura do Trabalho: Estudo de Psicopatologia do Trabalho. São Paulo: Cortez. 1992. 
DELORS, J.Y COLS Educação: um tesouro a descobrir. "Relatório para a UNESCO da Comissão Internacional sobre Educação para o século XXI". São Paulo: Cortez, MEC, UNESCO, 1998.

EXAME. As melhores empresas para você trabalhar. [S.1.: s.n.], n. , 2015.

FOGAÇA, A; SALM. Cláudio L. Educação, Trabalho e Mercado de Trabalho no Brasil. Ciência e Cultura vol.58 no.4 São Paulo Oct./Dec. 2006. <http://cienciaecultura.bvs.br/scielo.php?pid=S000967252006000400021\&script=sci_arttext > [ISSN 2317-6660]

GELLER, Lucio. Mudança tecnológica e emprego. In: Emprego e desenvolvimento tecnológico: Brasil e contexto internacional. São Paulo: Diese, 1998.

HERÉDIA, V. Novas tecnologias nos processos de trabalho: efeitos da reestruturação produtiva . Scripta Nova. Revista electrónica de geografía y ciencias sociales. Barcelona: Universidad de Barcelona, 1 de agosto de 2004, vol. VIII, núm. 170 (9). <http://www.ub.es/geocrit/sn/sn-1709.htm> [ISSN: 1138-9788]

MARCUSE, Herbert. Ideologia da sociedade industrial. Rio de Janeiro: Zahar, 1964.

MARX, Karl. Manuscritos econômico-filosóficos. São Paulo: Boitempo, 2006.

MILANESI, Karina ; COLLET, Neusa ; VIERA, Cláudia Silveira ; OLIVEIRA, Beatriz Rosana Gonçalves de . Sofrimento psíquico em Dejours. In: Seminário Nacional Estado e Políticas Sociais no Brasil, 2003, Cascavel-PR. Anais do Seminário Nacional Estado e Políticas Sociais no Brasil. Cascavel: Unioeste, 2003.

OLIVEIRA, N. T. Somatização e sofrimento no trabalho. Textos \& Contextos (Online), Porto $\begin{array}{lllllll}\text { Alegre } & \text { Rs, } & \text { v. } & 2, & \text { n. } 2^{\circ}, & \text { p. } & 1-14,\end{array}$ <http://revistaseletronicas.pucrs.br/teo/ojs/index.php/fass/article/view/958/738> [ISSN: 1677-9509]

ORSO, P. J. (Org.); GONCALVES, S. R. (Org.) ; LUZ, P. P. (Org.) ; ANJOS, A. L. S. (Org.) . Sociedade Capitalista, Educação e Lutas de Classes. 1. ed. São Paulo-SP: Outras Expressões, 2014. v. $1.33 p$. 
TOLFO, S. R. ; PICCININI, V. C. . As melhores empresas para trabalhar no Brasil e a Qualidade de Vida no Trabalho: disjunções entre a teoria e a prática. RAC. Revista de Administração Contemporânea, Curitiba, v. 5, n.1, p. 165-194, 2001.

TRAESEL ; MEGIER, M.C. A importância do reconhecimento no ambiente de trabalho. In: SEPE 2012 - Simpósio de Ensino Pesquisa e Extensão, 2012, Santa Maria. SEPE 2012 - Simpósio de Ensino Pesquisa e Extensão, 2012.

\footnotetext{
${ }^{1}$ Mestranda em Educação Brasileira. Universidade Federal do Ceará (UFC) pesquisadora - FUNCAP.

${ }^{2}$ Bacharel em Ciências Contábeis. Centro Universitário Estácio do Ceará (FIC).

${ }^{3}$ Bacharel em Administração. Universidade de Fortaleza (UNIFOR).

${ }^{4}$ Doutorando em Educação Brasileira - UFC; Mestre em Políticas Públicas e Sociedade - UECE; Engenheiro de Segurança do Trabalho; Professor da Universidade de Fortaleza - UNIFOR; Bolsista Hora Pesquisa - UNIFOR. Artigo apresentado à Universidade de Fortaleza como requesito para obtenção do título de especialista em Gestão de Pessoas, sob a orientação do doutorando Raphael de Souza Pires, Fortaleza 2015.

${ }^{5}$ É uma abordagem metodológica ao estudo da sociedade, da economia e da história que foi pela primeira vez elaborada por Karl Marx e Friedrich Engels (1818-1883). O materialismo histórico procura as causas de desenvolvimento e mudanças na sociedade humana nos meios pelos quais os seres humanos produzem coletivamente as necessidades da vida, na relação com o trabalho. As classes sociais e a relação entre elas, além das estruturas políticas e formas de pensar de uma dada sociedade, seriam fundamentadas em sua atividade econômica.

${ }^{6}$ Frederick Winslow Taylor (1856-1915), norte americano de Filadélfia, era um engenheiro mecânico que em 1911 desenvolveu uma obra chamada "Os princípios da administração", que continha uma série de métodos inovadores para a produção industrial. Taylor defendeu a ideia que o trabalhador deveria focar em sua parcela do processo produtivo e desempenhá-la no menor tempo possível, não precisando ter conhecimento do todo produzido, bem como evitar o gasto de energia "desnecessário", limitando seus atos apenas para a produção. Henry Ford (1863 - 1947) foi um empreendedor americano fundador da Ford Motor Company que, inspirado no método idealizado por Taylor, foi responsável pela criação de um sistema industrial chamado de fordismo. A grande inovação do fordismo em relação ao taylorismo foi à introdução de linhas de montagens, na qual o operário era responsável apenas por uma atividade. Esses dois métodos tinham o mesmo objetivo: ampliação do lucro dos detentores dos meios de produção, sem levar em conta os direitos ou as condições de trabalho dos trabalhadores.
}

RECEBIDO EM: Setembro de 2015

APROVADO EM: Abril de 2016 